\title{
Writing the History of Science
}




\title{
Science and Knowledge*
}

\author{
Roger Chartier
}

Over the past thirty years, the history of science has undergone a renaissance as profound as that affecting any other domain of historical study. The publication in 1985 of Simon Schaffer and Steven Shapin's Leviathan and the Air-Pump, if it did not usher in this wave of innovation, made it visible beyond the confines of the discipline. ${ }^{1}$ Alongside the history of scientific institutions and scholars, and in sometimes sharp dialogue with the historical epistemology of figures such as Alexandre Koyré and Georges Canguilhem, science studies offered new perspectives that no longer separated the analysis of the production of knowledge from its conditions of possibility. ${ }^{2}$ This approach allowed historians to turn their attention to the sites where the work of discovery takes place, to the tools and machines that make it possible, and to the practices of scholars and the forms of scientific publication. As research accumulated over the passing decades, an original project thus took shape, and with it new questions concerning the relationship between scholarly knowledge and technical expertise, the links between science, war, and government, and Western science's 
encounters with other kinds of knowledge about the natural world in territories that had been colonized or dominated by Europeans.

Published under the direction of Dominique Pestre, the three-volume Histoire des sciences et des savoirs does not offer an exhaustive assessment-a completely impossible undertaking - but rather an overview of the most pressing and pertinent questions concerning each of its three chosen periods: the three centuries separating the Renaissance and the Enlightenment; a long nineteenth century lasting from the final third of the eighteenth century to 1914 and understood as a time of "modernity and globalization"; and the twentieth century, seen as "the century of the technosciences." It is an impressive undertaking involving nearly 1,500 pages, sixty-one chapters (overviews, essays, and case studies), and sixty-eight authors. The present review cannot hope to discuss it comprehensively. At the very most, my discussion seeks to raise a few questions that a reading of the first two volumes has inspired in a historian of the early modern period, leaving the work of examining the third volume to more competent hands. As Christophe Bonneuil and Pestre underscore in their introduction, this final volume tackles a century in which relations between the sciences and "the sociopolitical or economic issues of the period" ${ }^{3}$ were profoundly transformed, the result not just of war and technological hopes and dreams, but also of their flip side: the awareness of the damage wrought by progress, increasing regulation in a time of triumphant liberalism, and competition in the production of knowledge brought about by the emergence of new actors, biopolitics, and the digital sphere.

The "century of the technosciences" is thus understood as coming to an end in the 2010s. Yet where should the scope of the collection begin once it has been decided, as Stéphane Van Damme writes, that the first volume "seeks to test the hypothesis of an 'Old Regime of science and knowledge"? 4 According to the contributors to the volume, this "Old Regime" (which paradoxically characterizes the onset of the "modern era") has various points of departure: the 1530s, with the introduction into natural history of plants unknown to the ancients ${ }^{5}$; the end of the fifteenth century, with its voyages of exploration and the first opening up of the world ${ }^{6}$; or 1400 , and the beginnings of a change "that was to gradually replace the medieval practitioners of scientia working in the networks of the premodern university with a new, secular community practicing the natural sciences and working outside the medieval ecclesiastical-Scholastic organization and sometimes even against it." ${ }^{\top}$

3. Christophe Bonneuil and Dominique Pestre, "Le siècle des technosciences (depuis 1914)," in Pestre, Histoire des sciences et des savoirs, 3:9-24, here p. 11.

4. Stéphane Van Damme, "Un ancien régime des sciences et des savoirs," in Pestre, Histoire des sciences et des savoirs, 1:19-40, here p. 20.

5. Marie-Noëlle Bourguet and Pierre-Yves Lacour, "Les mondes naturalistes: Europe (1530-1802)," in Pestre, Histoire des sciences et des savoirs, 1:255-81, here p. 256.

6. Lorraine Daston, "Philosophies de la nature et philosophie naturelle (1500-1750)," in Pestre, Histoire des sciences et des savoirs, 1:177-203, here p. 178. 
These vacillations reflect legitimate concerns. On the one hand, it is not possible to fix a single starting point for all the contributions. Neil Safier, for example, refuses to organize the history of scientific books around Gutenberg's invention because "we now know that the advent of printing transformed the world of science less profoundly than was once believed." ${ }^{8}$ On the other hand, "this does not amount to returning to a historiographical framework that postulates continuity between the Middle Ages and the early modern period." 'This wariness leaves two options: to only begin this history once "the medieval university had lost its luster, its knowledge and methods of working contested-once it had been circumvented" 10 ; or to accept the classic category of the "Renaissance" without being taken in by it, identifying it as the historic moment when the scientia of the universities' Scholasticismwhat Lorraine Daston, drawing upon an essay by Eileen Serene, describes as "a systematic knowledge of the necessary and universal causes that could be demonstrated with the help of logical syllogisms"-was called into question. ${ }^{11}$ It is up to medievalist historians to say whether the profound reappraisals of Scholasticism mean that it can still be defined as a collection of interpretive and argumentative techniques that were thrown into disarray by the return to non-Aristotelian ancient texts, the recourse to experimental procedures, and the mathematization of measurement. This is certainly a question worth raising, and one that has long been relevant to a body of work that, while seeming to defend the most radical vision of discontinuity, is nevertheless haunted by the connection between modern science and medieval theology: that of Alexandre Koyré. ${ }^{12}$

\section{Science and Knowledge or Science as Knowledge}

Yet another reason to raise this question can be found in the very title of the work, Histoire des sciences et des savoirs, which may render the exclusion of Scholastic knowledge debatable. The legitimate desire to avoid confining the project within the limits of a classic definition of science (or Science, with a capital S) makes it essential to consider the relationship between science and knowledge, a "tension" that Otto Sibum considers "constitutive of the history of science in Europe, at least since

8. Neil Safier, "Livres et cultures écrites des sciences," in Pestre, Histoire des sciences et des savoirs, 1:205-29, here p. 205.

9. Van Damme, "Un ancien régime des sciences et des savoirs," 20.

10. Dominique Pestre, "Savoirs et sciences de la Renaissance à nos jours. Une lecture de longue durée," in Pestre, Histoire des sciences et des savoirs, 3:461-85, here p. 462.

11. Daston, "Philosophies de la nature et philosophie naturelle," 184. See also Eileen Serene, "Demonstrative Science," in The Cambridge History of Later Medieval Philosophy: From the Rediscovery of Aristotle to the Disintegration of Scholasticism, 1100-1600, ed. Norman Kretzmann, Anthony Kenny, and Jan Pinborg (Cambridge: Cambridge University Press, 1982), 496-517.

12. Paul Vignaux, "Hommage à Alexandre Koyré. De la théologie scolastique à la science moderne," Revue d'histoire des sciences et de leurs applications 18, no. 2 (1965): 141-46. 
the start of the modern era." ${ }^{13}$ Such a tension lies at the basis of essential divisions, both historic and historiographical. Daston clearly indicated the effects of such a distinction in 2003:

The distinction between scientific and other types of knowledge has historically also been mirrored in a social distinction between those who work with their heads and those who work with their hands, and, at least since the eighteenth century, in a cultural distinction between lands (mostly West European) that have modern science and those that don't (everyone else). ${ }^{14}$

In differentiating between theory and practice, intellectual labor and manual labor, modern science and traditional knowledge, the terms used in the title of the three volumes published by Éditions du Seuil_- "sciences" and "savoirs"—appear to clearly distinguish between two sets of objects. In the two published volumes of Lieux de savoir, an ongoing project edited by Christian Jacob, these two sets are inscribed within a morphological perspective "attentive to subjects' material arrangements, gestures, and modes of interaction." ${ }^{15}$ Here, in Pestre's Histoire des sciences et des savoirs, they are located within a historical discontinuity. But is this enough to overcome all difficulties? Perhaps not.

In his "General Opening," Pestre characterizes the sciences as a particular category of knowledge, which leads to the notion of "scientific knowledge." Sometimes, the adjective "scientific" appears in the text between quotation marks; sometimes it does not. Thus, a paragraph noting "the variable definitions assumed by knowledge and 'scientific' knowledge in particular depending on the place and time" asserts that "scientific knowledge [this time without quotation marks] does not possess a transcendence that would radically set it apart from other ways of apprehending the real." 16 This hesitation regarding the use of quotation marks (which is echoed when it comes to the "scientific revolution") is not a matter of carelessness. It is a way of marking a distance from received significations that have been profoundly called into question, while at the same time recognizing that no alternative vocabulary or more rigorous set of definitions have been substituted for them.

To consider "scientific" knowledge a particular class of knowledge presents two problems. The first is editorial in nature. Among all of the knowledge that

13. H. Otto Sibum, "Les sciences et les savoirs traditionnels," in Pestre, Histoire des sciences et des savoirs, 2:285-303, here p. 285.

14. Lorraine Daston, "Knowledge and Science: The New History of Science," in Las ciencias sociales y la modernización. La fundación de las academias, ed. Miguel Herrero y Rodríguez de Miñon and Johannes-Michael Scholz (Madrid: Real academia de ciencias morales y políticas, 2002), 33-52, here p. 34.

15. Bertrand Müller, "Les lieux de savoir : un entretien avec Christian Jacob," Genèses 76, no. 3 (2009): 116-36, on Christian Jacob, ed., Lieux de savoir, vol. 1, Espaces et communautés (Paris: Albin Michel, 2007). The second volume, Les mains de l'intellect, was published in 2011. 
is not "scientific" but is nevertheless "a vehicle of truth and meaning," how to distinguish between that which must have a place in this history and that which must be excluded from it if the project is not to slide into some form of impossible total history? While technical and administrative knowledge-the knowledge of state and action-have been included and the arts, literature, metaphysics, and philosophy have been excluded, there is no clear decision (nor should there have been) when it comes to the forms of knowledge that Pestre refers to as "professional, popular, amateur, associative, or "traditional." 17 These forms of expertise cannot be radically distinguished from formalized, scientific, and technical knowledge and may even, as the third volume shows, come to compete with them in the modern world.

The second problem is an epistemological one. For some of the project's authors, the very attempt to draw a line between "scientific" and other types of knowledge is problematic. According to the first volume's editor, Stéphane Van Damme, the first move that must be taken if one is to break with "yesterday's genealogy of modern science" is to "renounce an a priori definition of the frontiers between science and knowledge in favor of studying not just the social and intellectual activity of boundary-making and demarcation, but also circulations, practices, and objects of research." ${ }^{18}$ For Rafael Mandressi, the study of printed anatomical, botanical, and zoological images, as he outlines it in this first volume, "leads to the revisiting of more fundamental divisions, particularly that which claims to distinguish (with a clarity that hardly belongs to the first European modernity) knowledge that is scientific from that which is not." ${ }^{19}$

Faced with this difficulty, the various essays take one of three positions. Must one contrast and distinguish between "science" and "knowledge"? Or should one instead see the former as a class of the latter? Or simply reject the distinction altogether? For some, "a truly historical conception of the history of science" must not ignore "pseudo-science." This is why, in their essay on the development of racial categories in the West between the Middle Ages and the eighteenth century, JeanFrédéric Schaub and Silvia Sebastiani insist that "the reader should not be surprised that the question of race has been included in this volume, as long as the discrepancy between racial theories and current knowledge in biology and the social sciences remains explicit." ${ }^{20}$

Another approach consists in substituting a multiplicity of domains of expertise and experience for the excessively blunt distinction between "science" and "knowledge." These may be described in various ways: as "fields of science" ("champs de sciences" is the title of the second part of each volume), "fields of knowledge," "fields of expertise," "'regimes' of scholarly practices," or "economies

17. Ibid.

18. Van Damme, "Un ancien régime des sciences et des savoirs," 21.

19. Rafael Mandressi, "Le regard scientifique : cultures visuelles des sciences," in Pestre,

Histoire des sciences et des savoirs, 1:231-53, here p. 250.

20. Jean-Frédéric Schaub and Silvia Sebastiani, "Savoirs de l'autre? L'émergence des questions de race," in Pestre, Histoire des sciences et des savoirs, 1:283-304, here p. 284. 
of knowledge." ${ }^{21}$ These distinctions are the condition of possibility for studying circulations, transfers, and translations among the various "fields," "regimes," or "economies" that coexist in a given society or at a given time. But they presuppose that the frontier separating them has already been demarcated.

This leads to a third proposition: defining "scientific" knowledge on the basis of a particular set of tools or the operations of a specific expertise. It is a definition of this type that Pestre sets out in his general introduction when he underscores the intricate relations "between the sciences and technical universes, between this knowledge and the productive, political, military, and imperial worlds." The "sciences" in question are here defined in terms of "ways of knowing based on controlled and instrumented experimentation, systematic observation, and the regularity of recordings, as well as on mathematical and statistical tools." 22 This is admittedly a restrictive definition, but it does have the merit of placing the distinction between science and knowledge contained in the work's title on a solid foundation.

It nevertheless raises a new series of questions. The first concerns the tension between two scientific paradigms: that proposed by the mathematicized knowledge of physics (the implicit reference of this definition) and that of philosophy and natural history. This contrast supplies the point of departure for Marie-Noëlle Bourguet and Pierre-Yves Lacour's essay:

Until the early 1990s, the history of science privileged astronomy and experimental physics over natural history. This long-standing disdain was due to the preeminence of mathematized knowledge over empirical knowledge and of experimental practices over observational practices. Between the sixteenth and eighteenth centuries, however, natural history was a socially and culturally dominant form of knowledge, and moreover played an early and essential role in the development of practices usually associated with the "scientific revolution." 3

The "scientific revolution": this return to quotation marks clearly suggests a second question, that of the chronology and modalities by which the practices and tools identified by Pestre came to impose themselves on other forms of expertise concerning the natural world or the human body-either because their specific techniques were appropriated by the dominant scientific paradigm or because they were deprived of their power to act as a vehicle for knowledge.

21. The categories "fields of knowledge" and "regimes' of scholarly practices" are used in Van Damme, "Un ancien régime des sciences et des savoirs," 25 and 27; "fields of expertise" in Bourguet and Lacour, "Les mondes naturalistes," 257; and "economies of knowledge" in Peter Dear, "Cultures expérimentales," in Pestre, Histoire des sciences et des savoirs 1:67-85, here p. 81 .

22. Pestre, "Écrire une histoire des sciences," 10.

23. Bourguet and Lacour, "Les mondes naturalistes," 255. 


\section{The Scientific Revolution}

Throughout the first volume of the Histoire des sciences et des savoirs, the "scientific revolution" is called into question, albeit in a complex and not necessarily unanimous manner. Some of the authors adopt the notion without quotation marks, as if it referred to a generally accepted historic reality. In her contribution on the role of academies, Maria Pia Donato thus writes of "the scientific revolution and, more generally, modern science." ${ }^{24}$ Similarly, after setting the expression between quotation marks in the first paragraph of their essay, Bourguet and Lacour subsequently abandon them when discussing the manner in which "curiosity gave the scientific revolution its 'factual sensibility." 25 Adopting Philippe Descola's arguments regarding the historicization of the distinction between nature and culture, in his study of the environmental sciences Grégory Quenet neglects to use quotation marks when he refers to "the scientific revolution of the seventeenth century that transformed the world into a well-ordered machine, its various elements linked by relations of causality that can be mathematically formulated and universalized." 26 And Peter Dear refers to it without name when he writes that "the new type of experimental science that emerged during the seventeenth century possessed a certain number of characteristics which distinguished it from other, older epistemologies also based on experimentation." 27

In the company of these authors, readers familiar with Koyré will not find themselves in alien territory. The scientific revolution took place and had a date: the seventeenth century. It spread according to two epistemological modalities, initially opposed but subsequently conjoined: the mathematical deciphering of a world written more geometrico and the production of knowledge via experimental practices that had to be replicated, authenticated, and therefore negotiated. This revolution thus identifies modern science with those "ways of knowing based on controlled and instrumented experimentation, systematic observation, and the regularity of recordings, as well as on mathematical and statistical tools." 28

Over the course of the essays, however, cracks begin to appear in this certainty as all formulations of the scientific revolution thus understood are called into question. In his study of the forms of scientific publication, Safier insists that "at a moment when the paradigm of the scientific revolution has been thoroughly challenged, it is urgent to show the diversity and complexity of the paths leading to the acquisition and transmission of knowledge."29 In her analysis of the knowledge produced by religious missions, particularly those of the Jesuits, Antonella

24. Maria Pia Donato, “'Faire corps': les académies dans l'ancien régime des sciences (XVII $-\mathrm{XVIII}^{\mathrm{e}}$ siècle)," in Pestre, Histoire des sciences et des savoirs, 1:87-109, here p. 87. 25. Bourguet and Lacour, "Les mondes naturalistes," 264.

26. Grégory Quenet, "L'environnement et ses savoirs," in Pestre, Histoire des sciences et des savoirs, 1:464-83, here p. 467.

27. Dear, "Cultures expérimentales," 67.

28. Pestre, "Écrire une histoire des sciences," 10.

29. Safier, "Livres et cultures écrites des sciences," 227. 
Romano justifies the attention paid to these new actors "at a time when specialists of the history of science and knowledge are challenging the grand narrative of modern science, the scientific revolution, and European modernity." ${ }^{30}$ Citing the work of Shapin and Margaret Osler in a note, Daston in turn takes up the critique of "what historians of science have traditionally called "the scientific revolution" on the grounds that "recent work in the field has called into question each term of this denomination-up to and including its definite article." For Daston, to assert the existence of a "particular, unique, and spectacular break with the past" is to fall prey to anachronistic illusion: "the developments were simply too numerous, taking place in domains that were too different and at rhythms that were too varied, to be perceived as a single phenomenon. It is only retrospectively and with a good dose of teleological perspective that they can appear as a unified process culminating in a single outcome." Nor did these developments usher in the era of modernity: "Whatever emerged from this, in 1750 it still did not resemble what we call 'modern science." "31 The supposed "scientific revolution" is thus rendered moot within an Old Regime of knowledge, that of natural philosophy—-the object of Daston's essay.

A lost paradigm, an obsolete grand narrative, an inadequate name: the very notion of the "scientific revolution" must be abandoned or, at the very least, squeezed between quotation marks indicating that whoever uses the expression has not been taken in by it. As Pestre observes in his general conclusion:

One thesis long prevailed: that of a scientific revolution which took place in Europe at some point between the sixteenth and eighteenth centuries. This revolution was painted in varying colors. It was a revolution in the way the world was seen (Copernican), a metaphysical revolution (Platonic), a revolution in the importance placed on facts (experimental), a revolution of numerical regularities (mathematical)—and always a revolution of the mind, of the gaze. Reading these three volumes makes it clear that this is perhaps too simple to be kept as it was. ${ }^{32}$

So be it. But what alternative models of understanding are put forward here?

The first, proposed by Daston, concerns the reorganization of knowledge of the natural world during the three centuries of the early modern period. The changes brought about by these transformations in knowledge are conceived along the same lines as Norbert Elias's notion of discontinuity, not as a sudden break with the past but rather as a reorganization of old and new elements: "It is undisputed that, during this period in Europe, everything that had to do with the knowledge of nature was radically reconfigured: what it was, the means used to achieve it, by

30. Antonella Romano, "Les savoirs de la mission," in Pestre, Histoire des sciences et des savoirs, 1:347-67, here p. 347.

31. Daston, "Philosophies de la nature et philosophie naturelle," 183 and 186 . See also Steven Shapin, The Scientific Revolution (Chicago: University of Chicago Press, 1998), and Margaret J. Osler, Rethinking the Scientific Revolution (Cambridge: Cambridge University Press, 2000).

32. Pestre, "Savoirs et sciences de la Renaissance à nos jours," 482. 
whom it was sought and for what purposes." 33 John Bennett Shank employs the same, very Eliasian term of "reconfiguration" to examine the transformations that led to the construction of a new figure of the scholar-a new persona in the sense of a cultural identity-over the course of the same centuries and even earlier. According to Shank, "between 1400 and 1750, Europe provided the stage for a reconfiguration of the social and institutional landscape that constituted legitimate knowledge, and a multitude of new personae associated with these new ways of knowing resulted from these changes." Here, the quotation marks around "scientific revolution" do not indicate a rejection of the notion but rather its definition as a process that took place over the longue durée: "It would be better to describe what has traditionally been called the 'scientific revolution' as the historic outcome of these multidimensional social and intellectual reorganizations." "34

A second option consists in placing the "scientific revolution" in the plural, thereby rejecting the definite article. This is the solution adopted by some of the authors in the second volume, including John Pickstone (who died in 2014 and to whom this volume is dedicated). For Pickstone, as for Thomas Kuhn, the first third of the nineteenth century saw a "second scientific revolution," understood as a "set of reconfigurations" that took place over a short period of time. Reference to a "second" scientific revolution obviously supposes that it was preceded by a "first" revolution in the seventeenth century, characterized by "interactions between the mathematical tradition and Baconian empiricism." Slow to establish themselves in practice, these interactions nevertheless prefigured the transformations that marked the beginning of the nineteenth century: "Perhaps we should consider the optics [of Isaac Newton] as a precursor, albeit a distant one, of several of the new physical sciences characteristic of the second scientific resolution." 35

In their introduction to the second volume, the editors Kapil Raj and H. Otto Sibum do not accept this perspective without hesitation. Prudently employing quotation marks, they recognize a set of transformations that, in the final third of the eighteenth century (and not the first third of the nineteenth), may be described as a "second scientific revolution." This explains why the volume unexpectedly begins not in 1830,1800 , or 1789 , but rather in 1763 with the end of the Seven Years' War-the first truly global war, involving military action on three continents. "All things considered," they write, "the final third of the eighteenth century thus seems a good point of departure for our project. What is more, this choice does justice to the phenomena of the 'second scientific revolution'-the revival and intensification of scientific activity, the emergence of new areas of interest like electricity, mechanics, and chemistry, and new values such as quantification and precision." 36

33. Daston, "Philosophies de la nature et philosophie naturelle," 183.

34. Shank, "Les figures du savant," 44.

35. John V. Pickstone, "Les révolutions analytiques et les synthèses du modernisme," in Pestre, Histoire des sciences et des savoirs, 2:33-53, here pp. 36 and 38.

36. Kapil Raj and H. Otto Sibum, "Globalisation, science et modernité. De la guerre de Sept Ans à la Grande Guerre," in Pestre, Histoire des sciences et des savoirs, 2:11-30, here p. 22. 
Yet Raj and Sibum share the critique of the notion of "revolution," which they reject in favor of "a process-centered conception of history":

It is in seeking to favor this conception of history as a process that we part ways with the traditional, "discontinuist" vision of the history of science as a shift from one revolution to another. We do not want to concentrate on the spectacular individual events that changed everything but rather on slower phenomena characterized by uneven development that took place over time, affording "history," "modernity," and "science" their mutually interlinked meanings. ${ }^{37}$

Three authors are cited as inspiration for such an approach: Reinhart Koselleck, for his definition of the concept of history; Akira Hayami, who introduced the concept of the "industrious revolution" to anglophone scholarship in 1992; and Jan de Vries, who adopted this concept in an article for the Journal of Economic History two years later. ${ }^{38}$

What is at stake in these oppositions, vacillations, and hesitations is in fact the various ways that the notion of "revolution" can be used to envisage historical discontinuity. Is it necessarily linked to spectacular and unique events, or can it refer to fundamental epistemological transformations-for example, the description of nature in the language of geometry or the concept of the infinite universe? Must these discontinuities be conceived as absolute, radical breaks that establish something that was not there before and suddenly appear without precursor or origins? Or should they rather be thought of as processes of recomposition that produce new configurations in which inherited and original knowledge are interwoven? The controversies surrounding these "scientific revolutions"-whether the first or the second-seem to refer less to the historical reality of the phenomena designated by the term than to historians' own conceptions of what makes for a revolution, scientific or otherwise.

\section{Connected Histories}

One the most striking innovations of the Histoire des sciences et des savoirs is its desire to reject a diffusionist perspective postulating the absolute primacy of Western science. Some of its titles clearly say as much: the second volume is entitled "Modernity and Globalization," and the third part of the first is called "The Globalization of Science and Knowledge?" The point is thus to set this history of science and knowledge in the context of that of circulations, connections, and exchanges. The program is firmly outlined by François Regourd in his essay on the Atlantic worlds

37. Ibid., 18.

38. Reinhart Koselleck, Futures Past: On the Semantics of Historical Time, trans. Keith Tribe (New York: Columbia University Press, 2004); Akira Hayami, "The Industrious Revolution" [1967], Look Japan 38/436 (1992): 8-10; Jan de Vries, "The Industrial Revolution and the Industrious Revolution," Journal of Economic History 54, no. 2 (1994): 249-70. 
of science, which seeks "to cast light on scholarly practices and original frameworks for scientific and technical elaboration dominated by notions of transmission, exchange, adaptation, translation, hybridization, identity, and mobility." 39 This is a project shared by all efforts to write a history in equal parts. As Quenet puts it: "The thesis of the incommensurability of European and non-European knowledge has been undermined by the localized study of their encounters and what seeks to be a more symmetrical approach to history." 40

This standpoint has informed a range of innovative studies. By fixing its attention on the circulation of objects, specimens, and knowledge, the history of the construction of expertise regarding the natural world foregrounds new actors, including religious missions, trade companies, and scientific expeditions. It enlarges the geography of scientific practices by underscoring the role played by cities like Mexico City or Philadelphia and that of colonial institutions open to autochthonous elites, such as the Hindu College in Delhi or the University of Calcutta. In some situations, these encounters provided the melting pot for what would otherwise have been impossible innovations. As Raj observes in his chapter on colonial India: "The proximity between actors from the two cultures ensured a porosity of practices, ideas, and discourses that significantly affected ways of doing. It therefore produced scientific and technical innovations that had no precursors in either of the two cultures." 41

But can the Indian case be taken as exemplary? There are several reasons to doubt this. The first concerns the indifference shown by some cultures to the knowledge brought by Europeans. According to Romain Bertrand, this was the case in maritime Southeast Asia, where networks of scholarly exchange existed well before the arrival of Europeans:

If the rulers of the Malay world generally exhibited such staunch indifference toward knowledge and technologies from Europe, it was because they had long been part of a dense transregional network of scholarly exchange running from Istanbul to the China Sea by way of the Holy Land and Gujarat. In their eyes, the knowledge carted around by the Europeans was very often secondary to the Indian, Chinese, Persian, and Arabo-Muslim cosmographies upon which they drew and to which they in their turn contributed. ${ }^{42}$

39. François Regourd, "Localités et centralités scientifiques: les mondes atlantiques," in Pestre, Histoire des sciences et des savoirs, 1:325-45, here p. 341.

40. Quenet, "L'environnement et ses savoirs," 468. See also Romain Bertrand, L'histoire à parts égales. Récits d'une rencontre, Orient-Occident (XVI $-X V I I^{e}$ siècle) (Paris: Éd. du Seuil, 2011); Quenet, "La tentation du monde: 'histoire globale' et 'récit symétrique," in À quoi pensent les historiens? Faire de l'histoire au XXI siècle, ed. Christophe Granger (Paris: Autrement, 2013), 181-96.

41. Kapil Raj, "Hégémonie impériale ou interaction constructive? L'Inde coloniale au XIX ${ }^{\mathrm{e}}$ siècle," in Pestre, Histoire des sciences et des savoirs, 2:305-25, here p. 307.

42. Romain Bertrand, "Les savoirs du commerce : le cas de l'Asie," in Pestre, Histoire des sciences et des savoirs, 1:306-23, here p. 319. 
Studied by Joanna Waley-Cohen, the historical knowledge of eighteenth-century Qing China was likewise closed to European imports (excepting the employment of two Jesuit painters). This doubtless also holds for spheres of knowledge other than history, though it is worth recalling the presence of French Jesuit mathematicians and astronomers in Beijing and the translation of the first six books of Euclid's Elements in the great eighteenth-century Chinese encyclopedia, the Siku Quanshu (1773-1782). The legitimate and fruitful attention paid to connected histories must not be allowed to obfuscate situations in which indifference to the other's knowledge was the rule-including when that other was European.

The desire for histories written in equal parts, though likewise legitimate and fruitful, does not diminish the profound asymmetry that governed practices of knowledge in the colonial context. Science by and for Europeans confined the inhabitants of colonized lands to the role of indigenous informers; it captured useful expertise (for example, in pharmacopoeia and medicine) and discredited knowledge considered as absurd or dangerous superstition. This is the conclusion reached by Romano in her study of missionaries and knowledge:

In their positions as astronomers or ethnologists, in their status as experts on the knowledge and cosmogonies of others, whether Mesoamerican or Asian, missionaries were confronted with various epistemes associated with relations to the divine that their first taskconversion-could only attribute to belief, the source of superstition, rather than to science, the producer of truth. ${ }^{43}$

Commenting on the work of Safier, Quenet points out that the vivacity of indigenous cultures and interconnections with Europeans, far from encouraging hybridities, were transformed into tools of capture:

The Amazonia of Safier reveals not only an indigenous world that had a perpetually shifting relationship to the environment before the arrival of the Europeans, but also a mosaic of interconnected trajectories in which travelers' experiences were informed by interactions with indigenous informers, before being transposed into narrative forms-lists, catalogues - that served as a vehicle for the imperial knowledge of nature. ${ }^{44}$

The encounter with indigenous knowledge was from the outset inseparable from the "domestication of the savage mind." 45

43. Romano, "Les savoirs de la mission," 363.

44. Quenet, "L'environnement et ses savoirs," 468. See also Neil Safier, Measuring the New World: Enlightenment Science and South America (Chicago: University of Chicago Press, 2008).

45. Jack Goody, The Domestication of the Savage Mind (Cambridge: Cambridge University Press, 1977). 
The second volume supplies many examples of how science was enlisted in the service of imperialism. This could be brutal and violent, as in "the complicity that developed between a number of sciences-natural history, comparative anatomy, biology, geography, cartography, ethnology, anthropology-in the global effort to racially hierarchize humanity. The cornerstone of raciology, this undertaking relegated whole swaths of the world's population to the status of inferiors, condemned by nature to slavery, exploitation, and colonial domination, or even supposedly predestined to imminent extinction at the hands of superior races." ${ }^{46}$ But imperial science could also take far more subtle forms.

Ilana Löwy flags this up regarding the use of microbial theories in the process of colonization, understood as a fight against tropical diseases: "The science of microbes is thus not just a way to do politics by other means; it is also a specific form of political intervention." ${ }^{47}$ Simon Schaffer in turn shows that metrology was not only a tool of colonial domination but must also be understood, as he puts it in one of his subheads, "as imperialism." Why? Because "without the reliable switchboards of sub-marine telegraphy, neither the longitude of temporary observation posts nor the British Army's communications network would have been assured. And the reliability of these cables depended on the reliability of the values of electrical metrology established in the new physics and engineering laboratories of [John J.] Thomson's Great Britain and [Werner von] Siemens's Germany." An unbroken chain thus linked laboratory experiments and the war machine. But this was not all: "The relationship between the values established in physics laboratories and those that supplied the basis for imperialism was even closer. Late nineteenth-century scientists joined networks that distributed machines, values, and standard practices across the entire world. Imperialism, mass production, and metrology dominated their universe." 48

Reading these essays dedicated to the study of the globalization of knowledge inspires several reflections. First, there is clearly a need to set circulation and exchange within the context of domination. The legitimate interest in hybridity has sometimes overshadowed the fact that, where it existed, it was situated within an asymmetrical relationship in which the powers of one party severely limited the possibilities open to the other. Of course, the colonization of territories, bodies, and imaginaries did not totally obliterate indigenous knowledge or preclude hybridization, but it did place this knowledge in a very unequal relationship. These volumes are a forceful reminder of this fact.

Next, situations of indifference or "hostile appropriation," as Michael Gordin calls them, argue against rejecting out of hand the resistances of the "Great

\footnotetext{
46. Bronwen Douglas, "Mondialisation, évolution et science des races," in Pestre, Histoire des sciences et des savoirs, 2:242-63, here p. 258.

47. Ilana Löwy, "Les microbes et les humains," in Pestre, Histoire des sciences et des savoirs, 2:222-41, here p. 237.

48. Simon Schaffer, "Modernité et métrologie," in Pestre, Histoire des sciences et des savoirs, 2:114-41, here pp. 125 and 130.
} 
Divide." ${ }^{\prime 9}$ This is not a suggestion to ignore non-European sciences-even if these volumes could not consider these sciences in themselves without becoming unwieldy, and are thus obliged to confine the critique of Eurocentrism to chapters necessarily centered on European sciences and their reception (or non-reception). Rather, it is to acknowledge the persistence of differences and boundaries that were affirmed as hierarchies and transformed, whenever possible, into domination.

Finally, in his chapter on "Western" science under the Meiji Restoration, Kenji Ito encourages us to rethink the fundamental question of the causes and strategies that led this Western science to be accepted as the only vehicle for exact and rigorous knowledge. As he puts it:

Why is it that some forms of knowledge retreated to the margins while Western science emerged as the unique model of science? I shall examine this question by considering situations in which different forms of knowledge were made to compete with one another and evaluated. ... What we call "Western science" consequently appears not only as a competitive form of knowledge, but also as a form of knowledge that was able to create and define the "combat zone" in a way that was to its advantage. ${ }^{50}$

Japan thus followed a trajectory that led from imitation to appropriation. As the third volume of the Histoire des sciences et des savoirs shows, however, Japan was far from the only place where "Western science' simply became 'science." 51

Far from diminishing its significance, the questions posed by (and to) this great intellectual undertaking directed by Pestre demonstrate the heuristic possibilities of science studies. By refusing to offer a transhistorical definition of science, by attending to the distinctions and relations between the various classes of knowledge, and by setting practices of knowledge in the context of their (theoretical, social, political, cultural) conditions of possibility, this project has generated a diverse and international historiographical production that only the most hostile critic would think to reduce to a form of sociological reductionism or epistemological relativism. Each of the chapters in these three

49. Michael Gordin, "What a Go-a-Head People They Are!': The Hostile Appropriation of Herbert Spencer in Imperial Russia," in Global Spencerism: The Communication and Appropriation of a British Evolutionist, ed. Bernard Lightman (Leiden: Brill, 2015), 13-34.

50. Kenji Ito, "La science 'occidentale' sous la restauration Meiji. Mimétisme ou appropriation intelligente?" in Pestre, Histoire des sciences et des savoirs, 2:346-65, here p. 348-49. 51. Ibid., 362. 
volumes is a perceptive and original essay. All offer new and often unexpected perspectives, provoke thought, and encourage, as they have here, discussion and debate.

Roger Chartier

Collège de France - EHESS 